\title{
IMPORTÂNCIA DE UMA ABORDAGEM INTERDISCIPLINAR NO PROCESSO DE ENSINO-APRENDIZAGEM PARA FORMAÇÃO DE TÉCNICOS EM AGROPECUÁRIA: EXPERIÊNCIAS VIVIDAS EM OFICINAS SOBRE O TEMA QUÍMICA DO SOLO
}

\author{
Jainara Pacheco de Braga ${ }^{1}$ \\ Otoniel Carvalho de Braga ${ }^{2}$ \\ Thiago Vieira da Costa $^{3}$ \\ Uberson Boaretto ${ }^{4}$
}

\section{INTRODUÇÃO}

$\mathrm{O}$ pH do solo está diretamente relacionado a disponibilidade de nutrientes para a cultura, visto que a disponibilidade de macro e micronutrientes para as culturas está relacionada com a quantidade de íons $\mathrm{H}^{+}$presentes no solo. A maioria dos solos apresenta $\mathrm{pH}$ inferior a 7, portanto quando nos referimos a esta característica química do solo a chamamos de acidez do solo. Há dois tipos de acidez do solo, a acidez potencial, que são os íons de Hidrogênio adsorvidos as partículas do solo, e a acidez ativa, que consiste na concentração de $\mathrm{H}+$ dissolvido na solução do solo. (Coelho, 1973).

Considerando a importância do ensino das características do solo e conceitos relacionados ao $\mathrm{pH}$ do solo presentes no currículo do técnico em agropecuária, vimos a oportunidade de desenvolver uma abordagem dinâmica e interdisciplinar, capaz de integrar conceitos de química aplicados à agricultura, tornando significativo o processo de ensino e aprendizagem. A partir da relevância de conhecer o $\mathrm{pH}$ do solo decidimos realizar uma oficina sobre a medição do $\mathrm{pH}$ do solo utilizando Bioindicadores de $\mathrm{pH}$, substâncias capazes de apresentar alguma alteração em sua estrutura química, cromaticamente perceptível, ao passarem por uma mudança de pH. Escolhemos a utilização de bioindicadores vegetais, devido à facilidade de extração, identificação e localização dessas plantas.

O grande desafio enfrentado por quem ensina química é o caráter abstrato que a disciplina pode apresentar. Por muitas vezes, isso faz com que o aluno não consiga relacionar os conteúdos abordados com situações do seu cotidiano, criando a impressão de que a química só acontece dentro de laboratórios. 
Cabe ao professor desmistificar esse pré-conceito e aproximar o estudante da disciplina, fazendo com que ele perceba e identifique a química ao seu redor.

Ainda mais importante que o conteúdo ministrado, é a abordagem metodológica adotada para transmitir tal conhecimento. É bastante discutida a importância da experimentação para facilitar o processo de ensino e aprendizagem e tornar significativo o processo de ensino e aprendizagem. De acordo com Bueno et al quando não há uma articulação entre a teoria e a prática os conteúdos são pouco relevantes à formação do indivíduo e pouco colaboram para seu desenvolvimento cognitivo.

Uma crítica recorrente ao ensino tradicional é direcionada ao modo como o aprendiz torna-se um mero espectador em sala de aula, não participando ativamente do processo de aprendizagem. É papel do facilitador do processo de ensino e aprendizagem tornar a aula atrativa, buscando relacioná-la com assuntos do cotidiano dos alunos, tornando-a convidativa para que questionem e sintam-se livres para contribuir com experiências (Guimarães, 2009). É também encargo do facilitador desenvolver metodologias de ensino multidisciplinares que busquem resgatar e valorizar os conhecimentos e vivências dos estudantes, estimulando o debate e construindo a aula juntamente com os alunos. Um dos objetivos da oficina é justamente resgatar e reforçar conceitos assimilados previamente pelos alunos através da correlação desses conhecimentos a alguns assuntos do cotidiano e da grade do curso técnico em Agropecuária. Fazendo isto, é possível a aquisição de conhecimentos mais concretos, que, consequentemente, serão fixados de maneira mais efetiva. Essa correlação do conteúdo com assuntos cotidianos aliados aos exercícios práticos visa a construção do saber científico.

Há inúmeros métodos de conhecer o pH de uma solução, os mais utilizados são o pHmetro e o papel tornassol. Portanto, há outro método bastante econômico e efetivo, a utilização de bioindicadores vegetais, que consiste em uma técnica simples e amplamente utilizada para conhecer o pH de uma solução aquosa. Além de efetivo, esse método é bastante didático, tendo em vista que a aprendizagem através das cores é amplamente difundida quando o assunto é ensino de química. De acordo com Dias (2003, p. 28) "a cor é um tema que motiva os alunos a aprender química", fato evidenciado pelos inúmeros trabalhos desenvolvidos utilizando essa abordagem de ensino. 
Bioindicadores de pH são substâncias com propriedades halocrômicas, ou seja, substâncias que variam sua coloração em função do pH do meio. Inúmeras espécies vegetais apresentam tal propriedade e são facilmente identificáveis por sua coloração que pode ser rosa, violeta, vermelha ou azul, podendo estar presente em diversos componentes da planta. A responsável por essas diferentes cores nas plantas é uma substância intitulada antocianina, um composto que pode ser encontrado em diferentes tecidos vegetais presentes em flores, frutos, caules e folhas. A propriedade das antocianinas demonstrarem cores distintas dependendo do $\mathrm{pH}$ do meio, faz com que elas sejam indicadores de $\mathrm{pH}$ (Rossi, 2002).

Uma grande vantagem na utilização de indicadores vegetais de $\mathrm{pH}$ é que esses compostos halocrômicos são biodegradáveis. Considerando a importância da redução de impactos ambientais para o desenvolvimento sustentável do agronegócio e da formação de um técnico responsável com a preservação dos recursos naturais, esta prática faz-se muito relevante, visto que o descarte das soluções tampão utilizados no preparo da técnica -que quando misturadas se neutralizam- é praticamente nulo, comparado a outras tecnologias de avaliação do $\mathrm{pH}$.

\section{METODOLOGIA}

Para elaborar a prática a ser executada com os alunos, foi necessário identificar plantas que demonstrassem a mais expressiva variação cromática em contato com os valores de $\mathrm{pH}$ propostos (4 a 8), que foram escolhidos de acordo com a faixa de valores de $\mathrm{pH}$ que apresentam a maioria dos solos. Para isto, fez-se necessário preparar soluções tampão de $\mathrm{pH}$ 4, 5, 6, 7 e 8, compostas de hidrogenofosfato dissódico $0,2 \mathrm{M}$ e ácido cítrico $0.1 \mathrm{M}$, além de $\mathrm{HCl} 0,1 \mathrm{M}$ e $\mathrm{NaOH}$ 0,1 M em diferentes quantidades, de acordo com a metodologia de Vogel (1979).

Preparadas as soluções tampão supracitadas, foram testadas mais de 35 diferentes plantas, com o intuito de identificar as espécies que seriam utilizadas durante as oficinas para medir o $\mathrm{pH}$ do solo. As plantas que apresentaram a mais visível variação cromática entre um e outro valor de $\mathrm{pH}$ foram as ornamentais Impatiens walleriana e Oxalis atropurpurea regnelli, conhecidas respectivamente como Beijinho e Trevo Roxo, ambas facilmente encontradas em canteiros e jardins. 
As amostras de solo que seriam objeto de estudo foram coletadas previamente no IFC câmpus Araquari pelos alunos do técnico em Agropecuária supervisionados pelos professores da disciplina de Solos e preparadas de acordo com a metodologia descrita por Malavolta et al (1997).

A oficina teve duração de 2 (duas) horas/aula e, a fim de facilitar o processo de ensino aprendizagem, a turma foi dividida em dois grandes grupos compostos por aproximadamente 12 alunos. A oficina foi separada didaticamente em duas etapas: a primeira que serviria como aporte teórico, fundamentando a relevância da prática que viria a ocorrer e esclarecendo alguns conceitos necessários. Buscamos resgatar conceitos já trabalhados pelos alunos na disciplina de química e em outras disciplinas relacionadas às áreas técnicas do módulo de produção vegetal, através de questionamentos dirigidos a toda a turma. A explicação teórica teve como norteador uma breve projeção de slides que serviriam para ilustrar e exemplificar o conteúdo abordado. Vale ressaltar que alunos com aprendizagem visual tem maior facilidade em fixar o conteúdo quando o relacionam com gravuras e imagens que ilustram o tema proposto.

A segunda etapa da oficina, que consistiu na prática de laboratório, se iniciou pela leitura e quitação das dúvidas a respeito do roteiro da aula prática e explicações das normas de segurança do laboratório de química. Inicialmente, um dos alunos pesou uma porção com $50 \mathrm{~g}$ de solo previamente seco e triturado que foi diluído em $100 \mathrm{~mL}$ de água e agitado, com o intuito de desprender os íons $\mathrm{H}^{+}$ contidos na solução e medir a acidez ativa do solo em água. Feito isso, os alunos, divididos em 4 (quatro) grupos, direcionaram-se a frente do laboratório para coletar alíquotas de $1 \mathrm{~mL}$ das soluções tampão e inseri-las individualmente em tubos de ensaio identificados. Um dos membros de cada equipe coletou uma alíquota de 1 $\mathrm{mL}$ da solução de solo e água, agora decantada, preparada no início da prática e a depositou em um tubo de ensaio individual.

Novamente reunidos nas bancadas, os alunos posicionaram paralelamente os tubos de ensaio com as soluções tampão em ordem do menor para o maior valor de $\mathrm{pH}$ e ao lado das soluções tampão colocaram o tubo de ensaio com a alíquota do solo. Paralelamente, outro membro do grupo fazia a maceração do indicador, utilizando cadinho e pistilo. A maceração da planta deveria ser feito após coletadas todas as alíquotas para impedir a degradação orgânica do extrato contendo o bioindicador. Feito isto, adicionaram 5 (cinco) gotas do bioindicador em 
cada tubo de ensaio contendo as soluções tampão e observaram a mudança de coloração, a fim de comparar a cor da alíquota pertencente a solução do solo com as demais e assim, conhecer o pH do solo. Ressaltando que o número de gotas de bioindicador adicionadas não interfere na prática, o importante é que seja utilizado o mesmo número de gotas para todos os tubos de ensaio, para não causar dúvidas na hora de avaliar a variação cromática.

No decorrer da atividade, buscou-se evidenciar a relevância da prática ao exercício profissional do técnico agrícola, enfatizando o uso de técnicas alternativas e da importância de conhecer o pH do solo. A fim de fixar os conteúdos abordados e avaliar o aproveitamento da oficina através do grau de assimilação dos alunos, foi aplicado um questionário contendo 4 (quatro) questões abertas ao término da oficina.

\section{RESULTADOS E DISCUSSÃO}

Percebemos interesse e envolvimento das turmas com o tema abordado e buscamos explorar os conceitos previamente adquiridos pelos alunos nas disciplinas técnicas específicas do curso de agropecuária e nas regulares do ensino médio. Buscamos associar a prática às atribuições e competências necessárias a um técnico agrícola para que este possa exercer seu trabalho de maneira competente. $\mathrm{A}$ determinação do $\mathrm{pH}$ do solo a partir da utilização de bioindicadores vegetais consiste em uma técnica consideravelmente simples e bastante acessível, tendo em vista que são necessárias somente soluções tampão na faixa de $\mathrm{pH}$ entre 4 e 8 e uma espécie vegetal que apresente variação cromática expressiva quando em contato com os diferentes valores de $\mathrm{pH}$ estudados, tendo em vista que as plantas com essa propriedade são facilmente encontradas em canteiros e jardins e identificadas pela cor, que varia de azul até vermelho, passando por tons de rosa e laranja.

Considerando também a importância da agroecologia para 0 desenvolvimento sustentável do agronegócio e para a formação de um técnico atento com suas responsabilidades ambientais, esta técnica faz-se muito relevante visto que o impacto ambiental gerado pelo descarte das soluções tampão - quando misturadas apresentam $\mathrm{pH}$ neutro - pode ser desconsiderado se comparado com as tecnologias atuais para determinação do $\mathrm{pH}$. 
Ao término da oficina, foi aplicado um questionário contendo 4 questões discursivas, contemplando o tema abordado ao longo da oficina e a relevância da prática para a atuação como técnico agrícola. Com as respostas obtidas no questionário e os questionamentos feitos pelos alunos ao longo da prática, foi possível perceber que os alunos deram a devida importância à nova técnica, reconhecendo que esta poderia ser utilizada por eles no desempenho dos seus serviços como técnico agrícola. Além deste, foi aplicado também um questionário a fim de medir o aproveitamento da oficina ministrada. A partir dos dados contidos neste $2^{\circ}$ questionário percebemos a relevância de uma oficina fundamentada no tema $\mathrm{pH}$ do solo e como esta abordagem facilitou o processo de ensino e aprendizagem, especialmente na assimilação de conteúdos, sobretudo os conteúdos relacionados à área de química, que normalmente são conteúdos de difícil assimilação pelos alunos do ensino médio, fazendo-se necessário uma abordagem mais dinâmica. Percebemos também que os futuros técnicos demonstram maior interesse na aprendizagem do conteúdo quando se estabelece uma relação entre o conteúdo abordado e atuação dos mesmos no mercado de trabalho. Portanto, mostrou-se mais uma vez que uma abordagem interdisciplinar pode ser amplamente explorada, sobretudo quando ocorre uma conversação e troca de experiências entre os professores e licenciados das mais diversas áreas do conhecimento.

\section{CONCLUSÃO}

Assi

$\mathrm{m}$, pudemos constatar que a abordagem de aulas experimentais no formato de oficinas para o ensino da química do solo mostrou-se muito promissora, especialmente para o ensino de alunos do curso técnico em agropecuária integrado ao ensino médio. Percebemos que houve uma maior facilidade na assimilação de conteúdos pertencentes à grade do curso e também o reconhecimento da oficina como prática enriquecedora para a sua formação como técnicos agrícolas, isso graças as constantes menções a importância da capacitação de técnicos capazes de apresentarem aos agricultores técnicas diferenciadas para a realização de procedimentos indispensáveis a prática agrícola, como é o caso da determinação do $\mathrm{pH}$ do solo. 


\section{REFERÊNCIAS}

ANTUNES, M. et al. pH do solo: Determinação com indicadores ácido-base no ensino médio. Química Nova na Escola. vol. 31, № 4, p. 283-287, nov/2009.

BUENO, L. et al. $O$ ensino da química por meio de atividades experimentais: a realidade do ensino nas escolas. Universidade Estadual Paulista "Júlio de Mesquita Filho".

COUTO, A.B., RAMOS, L.A., CAVALHEIRO, E. D. T. Aplicação do pigmento de flores no ensino da Química. Química Nova, 21(2), 1998.

DIAS, M. V.; GUIMARÃES, P. I. C.; MERÇON, F. Corantes naturais: Extração e uso como indicadores de pH. Química Nova na Escola, № 17, mai/2003.

GUIMARÃES, C. C. Experimentação no ensino de química: Caminhos e descaminhos rumo à aprendizagem significativa. Química Nova na Escola, vol. 31, № 3, ago/2009.

MALAVOLTA, E,; VITTI, G. C,; OLIVEIRA, S. A. Avaliação do estado nutricional das plantas: princípios e aplicações. 2. ed. Piracicaba: POTAFOS, 1997. 319p.

ROSSI, A. V.; TERCI, D. B. L. Indicadores naturais de pH: usar papel ou solução? Quim. Nova, vol. 25, № 4, p. 684-688, 2002.

SANTOS, L. G. V., RODRIGUES, L. B., LIMA, P. G., SOUSA, T. O., NETO, J. J. G. C., CHAVEZ, D. C. Indicadores naturais ácido-base a partir de extração alcóolica de pigmentos das flores Hibiscus rosa-sinensis e Iroxa chinensi, utilizando materiais alternativos. XII CONNEPI/Congresso Norte Nordeste de Pesquisa e Inovação.

VOGEL, A. Vogel's textbook of macro and semimicro qualitative inorganic analysis. $5^{\text {a }}$ Edition

YOSHIOKA, M. H., LIMA, M. R. Experimentoteca de solos: pH so solo. Programa solo na escola. Departamento de Solos e Engenharia Agrícola da UFPR. 